\title{
An Analytical Study on Knowledge Sharing in Web based Education
}

\author{
C.Pooranachandran \\ Dept. of Computer Science \\ HH The Rajah's College \\ Pudukkottai, India
}

\author{
Dr. R. Balasubramanian \\ Dept of Computer Applications \\ ETBT Group of Institutions \\ Erode, India
}

\begin{abstract}
The focus of Higher Education (HE) in the present scenario is global based and it has been growing appreciably facing challenges in the process of evolving as a commercial one. This global approach has created an awareness amongst HE institutions to revamp their methodologies in teaching and related issues. In the recent days, Information and Communication Technology (ICT) education is followed in the HE institutions and the conventional classroom is converted into Web Based Education (WBE). Though it is acclaimed as a good method, there are some setbacks in the process of Knowledge Sharing (KS) among the learners. This paper explores the possible ways to establish WBE using Social Computing Tools to facilitate Knowledge Sharing and create a social network among all the members of WBE. Social Network Analysis (SNA) techniques have been used to study KS patterns which take place between students and Web Based course. This SNA graph reveals the structure of social network highlighting connectivity, clustering and strength of relationships between students.
\end{abstract}

\section{Keywords: Web Based Education, Knowledge} Management Knowledge sharing, Social Network

\section{INTRODUCTION}

Knowledge Management (KM) is an important aspect in this current business world which has been undergoing dynamic changes from time to time. At the same time, Educational aspects also have to undergo positive changes in terms of teaching and learning as well. ICT is one of the modern methods that enables educational institutions to use Web facility to promote Web Enabled or Based education. Technology based education sometimes reduces face to face communication chances and involve social, cultural and linguistic differences. This method provides privacy as positive aspect. At the same time it cuts down physical interaction and appropriate cues among students. This method has led to some negative aspects such as lack of trust and unwillingness to share information. Many Higher Education institutions look for KM to find solution for such problems. KM literature exposes the fact that there is strong relationship between knowledge sharing and socialisation.

The SECI model [6] states that KS is an integral aspect in KM and also the process of converting new knowledge through sharing experiences in day-to-day interactions. So, the development of KS in WBE is concerned with providing a rich and meaningful platform for Knowledge Sharing among all the members in the learning environment. This paper proposes to deploy social computing tools as part of WBE to encourage KS among fifteen learners. The remainder of the paper is organised in the following section. In section 2, KM definition, $\mathrm{KM}$ activities, role of social software in KS are briefly explained. In section 3, we describe Web Based Learning Environment and KS arrangement. Section 4 provides KS analysis and discussion on the result obtained. In section 5, a snapshot of graphical representation of $\mathrm{KS}$ pattern among the learners is given. As a conclusion, the indication that the line of research can be continued with other SNA metrics to get more insights on KS pattern among the on-line learners.

\section{KM - DEFINITION}

Knowledge Management is a relatively new and a multidisciplinary aspect. There is no universally agreed definition for knowledge management, even among KM experts. In the context of this paper, the term could be defined as the systematic activities or process of identifying, capturing and sharing the knowledge which people can use to improve social development outcomes.

\subsection{KM Activities}

KM core activities include the creation and integration of knowledge, the accumulation and utilisation of knowledge, and the learning and sharing of knowledge and together, these comprise knowledge management [8]. Among these, knowledge sharing, or flow, or knowledge transfer is key to the success of knowledge management[2][7].

Knowledge sources are going to be the primary force to determine new products, services and approaches and growth of an organisation. According to Nonaka and Takeuchi [6] "everyone has become knowledge worker" and they highlighted that everyone has the potential of fostering knowledge sharing. We also agree with Kang, Morris, and Snell [3] that it is important for learners to share their knowledge with peer group. Several research studies have been conducted and reported regarding the significance of knowledge sharing among active and inactive learners

\subsection{Role Of Social Software In KS}

Until recently, most of the KS efforts were focused on the creation of central knowledge repositories, encouraging knowledge reuse and collaboration based on these repositories, in a typical top-down approach where knowledge was seen as a separate entity. The emerging Social Software offers a chance to complement this approach with tools that are simpler and more flexible. This type of software is actually not new at all software applications having similar traits have been in use for quite some time - but it is only recently that these have been labelled as "Social Software". Social Software is the term used to designate, "the use of computing tools to support, extend, or derive added value from social activity - Including weblogs, instant messaging, music and photo sharing, mailing lists and message boards, and online social networking tools" [4]. 
Social software definitions also have a common focus on the importance of creating networks and relations between people and the support of group interaction and it can be defined as software that enables communication through digital technologies helping people connect, converse, collaborate, manage content, and form online networks in a social and bottom-up fashion.

\section{WBE - COURSE}

WBE for the course " Programming in C "is intended to provide students with specific knowledge of the typical features that characterize program development in $\mathrm{C}$. The platform offers the following web-based learning resources: course material for theory and practical, sample programs, power point presentations, special fill-in forms to support individual and group activities and select social computing tools for the purpose of knowledge sharing activities.

\subsection{Knowledge Sharing Arrangements}

Learners could share, collaborate and help each other through the discussion forums_available on the learning platform, so that peer-to-peer knowledge sharing is encouraged. Learners are encouraged to use this resource not only to solve technical problems but also to exchange suggestions and information or help each other while completing the didactic activities assigned.

\section{KNOLWEDGE SHARING ANALYSIS AND DISCUSSION}

\subsection{Matrix Representation}

The use of discussion forum in WBE enables learners to carry out significant amount of $\mathrm{KS}$ activities. It also enables individuals form social relationships (contact) with other individuals without geographical constraint. Discussion between learners is usually logged and it provides an insight into the knowledge exchanged between individuals. The use of such data for identifying 'the knowledge and the knowledgeable' person is the main problem of interest in this research. The frequency of knowledge shared by a learner is represented in adjacency matrix and it is shown in Table 1 . The row represents number of times knowledge goes from a learner and column represents number of times knowledge received by learner. The matrix is given below:

Table 1- Adjacency Matrix

\begin{tabular}{|c|c|c|c|c|c|c|c|c|c|c|c|c|c|c|c|}
\hline & L0 & L1 & L2 & L3 & L4 & L5 & L6 & L7 & L8 & L9 & L10 & L11 & L12 & L13 & L14 \\
\hline L0 & 4 & 6 & 4 & 9 & 5 & 18 & 5 & 6 & 4 & 3 & 4 & 2 & 5 & 2 & 0 \\
\hline L1 & 5 & 2 & 2 & 10 & 11 & 9 & 8 & 7 & 0 & 3 & 11 & 7 & 7 & 6 & 0 \\
\hline L2 & 1 & 3 & 2 & 3 & 2 & 4 & 2 & 1 & 1 & 4 & 3 & 2 & 4 & 0 & 0 \\
\hline L3 & 4 & 12 & 2 & 1 & 10 & 4 & 7 & 5 & 0 & 3 & 9 & 3 & 2 & 4 & 0 \\
\hline L4 & 2 & 6 & 4 & 9 & 1 & 6 & 7 & 6 & 0 & 2 & 13 & 7 & 4 & 1 & 0 \\
\hline L5 & 8 & 15 & 2 & 14 & 13 & 1 & 10 & 7 & 0 & 2 & 7 & 6 & 6 & 4 & 0 \\
\hline L6 & 0 & 6 & 3 & 5 & 9 & 6 & 0 & 1 & 0 & 3 & 8 & 3 & 2 & 4 & 0 \\
\hline L7 & 0 & 4 & 2 & 4 & 3 & 6 & 0 & 1 & 1 & 1 & 5 & 3 & 2 & 0 & 0 \\
\hline L8 & 0 & 1 & 1 & 0 & 0 & 0 & 1 & 1 & 0 & 1 & 0 & 0 & 0 & 0 & 0 \\
\hline L9 & 0 & 2 & 8 & 0 & 3 & 6 & 6 & 6 & 0 & 0 & 1 & 5 & 11 & 3 & 0 \\
\hline L10 & 0 & 6 & 3 & 7 & 11 & 1 & 9 & 3 & 0 & 6 & 1 & 5 & 5 & 7 & 0 \\
\hline L11 & 0 & 1 & 2 & 1 & 2 & 4 & 6 & 4 & 0 & 8 & 0 & 0 & 0 & 2 & 0 \\
\hline L12 & 1 & 0 & 1 & 1 & 2 & 2 & 3 & 5 & 0 & 2 & 2 & 1 & 0 & 1 & 0 \\
\hline L13 & 0 & 5 & 3 & 3 & 7 & 5 & 7 & 2 & 0 & 4 & 4 & 2 & 4 & 0 & 0 \\
\hline L14 & 0 & 0 & 0 & 0 & 0 & 0 & 0 & 0 & 0 & 0 & 0 & 0 & 0 & 0 & 0 \\
\hline
\end{tabular}




\subsection{KS Density}

UCINET [1], a network analysis software, can be used to map and measure of relationship and sharing among learners. It is a method for visualizing our learners and connection power, leading us to identify different patterns of knowledge sharing. The results from UCINET show that the density value of KS among 15 students is 3.39 and standard deviation of 3.47. The density value represents the average number of knowledge shared by any pair of learners. With help of dichotomized matrix representation one can easily know the percentage of class involved in the task of sharing knowledge sharing. The density value is found to be 0.7333 . This is a good density index for a class size of 15 learners.
This implies that arrangement made in the web based learning environment facilitates higher level of knowledge sharing among the learners.

\subsection{Knowledge Flow}

In table 2, Learner's In-degree and Out-degree are shown. Learner's out-degree (knowledge transferred) varies between 0 and $94(\mathrm{M}=47.2, \mathrm{SD}=26.16)$ and in -degree ( knowledge received) between 1 and $77(\mathrm{M}=, 47.2 \mathrm{SD}=23.59)$. The most active learners and knowledge providers in the space are L1 and L5, L4 and L6 receive the highest number of knowledge. There are six learners who have a very low out degree, meaning that their contribution in knowledge sharing was is not encouraging

Table 2 : Knowledge Flow (In-degree, Out-degree)

\begin{tabular}{|c|c|c|c|c|c|c|c|c|c|c|c|c|c|c|c|c|}
\hline No. & 1 & 2 & 3 & 4 & 5 & 6 & 7 & 8 & 9 & 10 & 11 & 12 & 13 & 14 & 15 \\
\hline Learner & L5 & L1 & L0 & L4 & L3 & L10 & L9 & L6 & L13 & L7 & L11 & L2 & L12 & L8 & L14 \\
\hline Out-Degree & 94 & 86 & 73 & 67 & 65 & 63 & 51 & 50 & 46 & 31 & 30 & 30 & 37 & 5 & 0 \\
\hline In-Degree & 71 & 67 & 21 & 78 & 66 & 67 & 42 & 71 & 34 & 54 & 46 & 37 & 52 & 6 & 0 \\
\hline
\end{tabular}

\subsection{Knowledge Brokers}

Betweenness centrality helps to identify knowledge brokers and gatekeepers within a network. It is a measure of the extent that a network learner's position falls on the geodesic paths among other learners of a network. Thus, it determines whether a learner plays a (relatively) important role as a broker or gatekeeper of knowledge flows with a high potential for control on the indirect relations of the other learners.
Table 3 shows that the Betweenness values vary from 0 to $7.9(\mathrm{M}=1.6, \mathrm{SD}=2.0)$. The calculation has been made after symmetrising the adjacency matrix, through the minimum of the values (in this way, strong ties are kept). The four highest values are those of L2, L5, and L7. They are the gatekeepers and they can regulate the flow of knowledge in the network. The lowest Betweenness values are for L1, L3, L6, L8, L9, L10, L11, L12, L13, and L14. They can be considered outsiders in knowledge sharing.

Table : 3 Betweenness

\begin{tabular}{|l|c|c|c|c|c|c|c|c|c|c|c|c|c|c|c|}
\hline Learner & L5 & L2 & L7 & L4 & L1 & L3 & L12 & L9 & L10 & L6 & L11 & L13 & L0 & L8 & L14 \\
\hline Betweenness & 7.9 & 7.9 & 4.9 & 2 & 1.7 & 1.7 & 1.4 & 0.8 & 0.6 & 0.6 & 0.5 & 0.4 & 0.1 & 0 & 0 \\
\hline
\end{tabular}

\subsection{Structural Analysis}

In order to study the structural analysis of the group, clique analysis has been done. Clique is the maximum number of actors who have all possible times present themselves. Cliques are located by dichotomizing and symmetrizing the adjacency matrix at level three. The SNA analysis by UCINET has found six cliques.
1: L1 L3 L4 L5 L6
2: L0 L1 L3 L5
3: L1 L3 L5 L7
4: L1 L3 L4 L6 L10
5: L1 L5 L6 L13
6: L1 L6 L10 L13

The size of the cliques ranges from a clique with four members to a clique with five members. There are a lot of inter-clique connections. L1, in six ; L3,L5 and L6 in 4; L10,L13 in two; L0 and,L7 were in only one of these sub-groups 


\section{KS NETWORK IN WBE}

Figure -1 : Knowledge Sharing Network

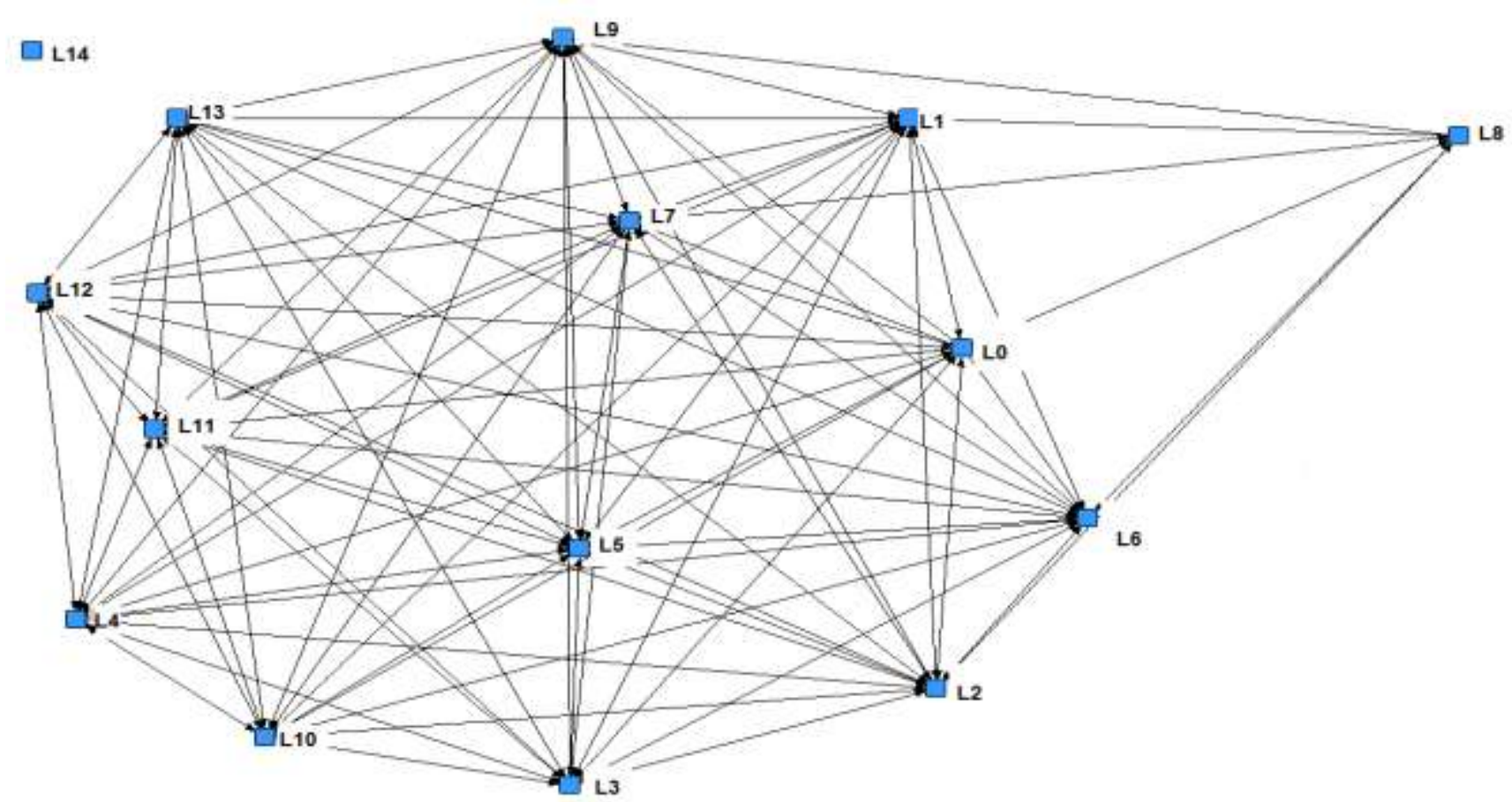

In the WBE, there are 15 learners. Figure 1 is a KS Network that shows the structure of the state of the network that evolved from the WBLE. The nodes represent the learner (the names of learners have been renamed L0 - L14 for reasons privacy and anonymity reasons). When there is a line directly connecting two nodes then these nodes are adjacent. When a node is one of a pair of nodes defining the line then the node is incident to the line. The number of lines that are incident with it is called nodal degree [9]. In-degree is the number of lines that are incident to a node while out-degree is the number of lines that are incident from it. Nodes whose degree equals 0 are called isolates. The KS network integrates all learners except for one isolate(L14)

\section{CONCLUSION}

In this paper, an analysis of KS in WBE, using social network analysis is presented. In addition, several common social network analysis metrics, such as in-degree, out-degree, betweenness, clique, and community are presented. Each metric serves different purposes. For example, in-degree and outdegree are used to measure one's connection with others; betweenness is used to measure a user's importance in terms of bridging users together; and clique metrics is used to identify like-minded groups. In future, it is planned to extend the current study to examine other centrality measures such as closeness and hub, and their implications for the KS. Applying social network analysis for understanding on-line educational systems is an ongoing research area, and it is assumed that this study contributes to its continued growth.

\section{REFERENCES}

[1] Borgatti, S. Everett, M. \& Freeman, L.C. (1992), UCINET IV, Version 1.0,Columbia: Analytic Technologies

[2] Gupta, A. and Govindarajan, V. (2000) 'Knowledge management's social dimension: Lessons from Nucor Steel', Sloan Management Review, Fall, pp. 71-80

[3] Kang, S., Morris, S. \& Snell, S.A. (2003). Extending the human resource architecture: Implications from social capital theory. Working paper

[4] Lawley, E. (2004). Blog research issues. Retrieved, from http://www.corante.com/many/archives/2004/06/24/blog_r esearch_issues.php

[5] Nonaka, I. (1998). The Knowledge-Creating Company. Harvard Business Review on Knowledge Management, Boston: Harvard Business School Press

[6] Nonaka, I., \& Takeuchi, H. (1995). The KnowledgeCreating Company. New York: Oxford University Press

[7] Szulanski, G. (1996) 'Exploring internal stickiness: Impediments to the transfer of best practice within the firm', Strategic Management Journal, vol. 17, pp. 27-43.

[8] Shieh-Cheih, F., Fu-Sheng, T. and Kuo-Chien, C. (2005) 'Knowledge sharing routines, task efficiency, and team service quality in instant service-giving settings', The Journal of American Academy of Business, vol. 6, no. 1.

[9] Wasserman, S., \& Faust, K. (1994). Social Network analysis and applications. Cambridge: Cambridge University Press 